\title{
Financial Leverage, Corporate Investment, and Stock Returns
}

\author{
Ali K. Ozdagli
}

\begin{abstract}
:
This paper presents a dynamic model of the firm with risk-free debt contracts, investment irreversibility, and debt restructuring costs. The model fits several stylized facts of corporate finance and asset pricing: First, book leverage is constant across different book-to-market portfolios, whereas market leverage differs significantly. Second, changes in market leverage are mainly caused by changes in stock prices rather than by changes in debt. Third, when the model is calibrated to fit the cross-sectional distribution of book-to-market ratios, it explains the return differences across different firms. The model also shows that investment irreversibility alone cannot generate the cross-sectional patterns observed in stock returns and that leverage is the main source of the value premium.
\end{abstract}

\section{JEL Classifications: G1, G3}

Ali Ozdagli is an economist in the research department of the Federal Reserve Bank of Boston. His e-mail address is ali.ozdagli@bos.frb.org.

This paper, which may be revised, is available on the web site of the Federal Reserve Bank of Boston at http://www.bos.frb.org/economic/wp/index.htm.

This paper is a modified and improved version of my Ph.D. thesis with the same title. I am grateful to Fernando Alvarez, Lars Hansen, Anil Kashyap, and Robert Lucas for their support. I also thank Federico Diez, Sergey Kulaev, Christina Wang, and the seminar participants at the University of Chicago, in particular, Gene Fama and Jarda Borovicka, for helpful comments, and Sarojini Rao for excellent research assistance. The usual disclaimer applies.

The views and opinions expressed in this paper are those of the author and do not necessarily represent the views of the Federal Reserve Bank of Boston or the Federal Reserve System.

This version: November 13, 2009 


\section{Introduction}

Firms with a high ratio of book value of equity to market value of equity (value firms) earn higher expected stock returns than firms that have low book-to-market equity ratio (growth firms). However, as Grinblatt and Titman (2001) point out, conventional wisdom tells us that growth options should be riskier than assets-in-place:

Consider Wal-Mart, for example. The value of this firm's assets can be regarded as the value of the existing Wal-Mart outlets in addition to the value of any outlets that Wal-Mart may open in the future. The option to open new stores is known as a growth option. Because growth options tend to be most valuable in good times and have implicit leverage they contain a great deal of systematic risk.

Therefore, as Zhang (2005) stresses, conventional wisdom suggests that growth firms, which derive their value from growth options, should have higher expected stock returns than value firms, which derive their value from assets-in-place.

To add insult to injury, Fama and French (1992) show that portfolios of stocks with different book-to-market ratios have similar riskiness as measured by the standard Capital Asset Pricing Model (CAPM) of Sharpe (1964), Lintner (1965), and Black (1972). This

phenomenon, known as the "value premium puzzle," helped the Fama and French model replace the CAPM as the benchmark in the asset pricing literature.

This paper explains the differences between the stock returns of value and growth firms. For this purpose, I extend the investment irreversibility model of Abel and Eberly (1996) by incorporating investors' risk preferences, risk-free debt contracts, and debt adjustment costs. Using this framework, I show that financial leverage can explain the major share of the value premium, while investment irreversibility alone generates a growth premium rather than a value premium. However, investment irreversibility is still an important ingredient that improves the model's fit with the data, by generating a wide range of bookto-market values.

The financing decisions in this model are similar, but not identical, to those of Fischer, Heinkel, and Zechner (1989) and Gomes and Schmid (2009). Those papers add debt restructuring costs to the standard tradeoff theory of capital structure whereby a firm chooses its financing policy by balancing the costs of bankruptcy against the benefits of debt, such as tax shields due to interest payments. My paper also assumes that firms benefit from the tax shield of debt as in the tradeoff theory and that they face additional costs at the time of debt restructuring. However, in this paper, debt has two properties distinct from its proper- 
ties in previous papers: it is risk-free and endogenously limited by the lenders to a certain fraction of capital.

The choice of risk-free debt serves simplicity, conformity to data, and consistency: First, it simplifies the analysis of the model by removing the need to keep track of the market value of leverage separately. Second, it fits the facts, presented in Fama and French (1993), that the book-to-market factor does not affect bond returns and that "average excess bond returns are close to zero" so that "the hypothesis that all the corporate and government bond portfolios have the same long-term expected returns cannot be rejected"(6). Finally, because we do not observe the market value of debt, many studies that relate risky debt to returns use book value of leverage as a proxy for market value of leverage. However, this contradicts the assumption of risky debt, and so the approach defeats the purpose. Therefore, for the sake of consistency, I stick to risk-free debt.

The debt limit of a firm is determined endogenously in the following way: Since interest payments are tax deductible, the firm prefers debt financing to equity financing and would rather have an infinite amount of debt. However, this leads to negative equity value in some states, so that the firm would rather go bankrupt than pay its debt. Therefore, for debt to remain risk-free, lenders will limit the amount of debt. They can accomplish this by accepting the resale value of capital as collateral and ensuring that this value is not lower than the amount of debt, so that they can recover their money in case of bankruptcy 1 Alternatively, lenders may limit the amount of debt in order to ensure that the market value of equity is always non-negative and that bankruptcy is suboptimal for the firm. I show that the market value of equity is strictly positive when the debt capacity equals the resale value of capital. Therefore, the market value of equity would still be non-negative if the lenders would lend the firm more than the resale value of its capital. Thus, the latter policy provides the firm with a higher debt capacity and the firm prefers this latter debt policy, while the lenders are indifferent.

An important property of the model is that the firm's book leverage, that is, the fraction of total capital supplied by lenders, is not state-dependent. The book leverage is determined in a manner that ensures that the firm value is non-negative even in the worst-case scenario, to avoid bankruptcy. I show that this worst-case scenario is independent of the state variables and hence a revision of the debt agreement at a later date would lead to the same level of leverage. As a result, it is not optimal for a firm to change its book leverage once it is set, and the book leverage remains the same across firms with different ratios of bookto-market equity, whereas market leverage differs significantly. Figure 1 plots averages of

\footnotetext{
${ }^{1}$ This is a common assumption in the papers that model risk-free debt. A recent example is Livdan, Sapriza, and Zhang (2009).
} 


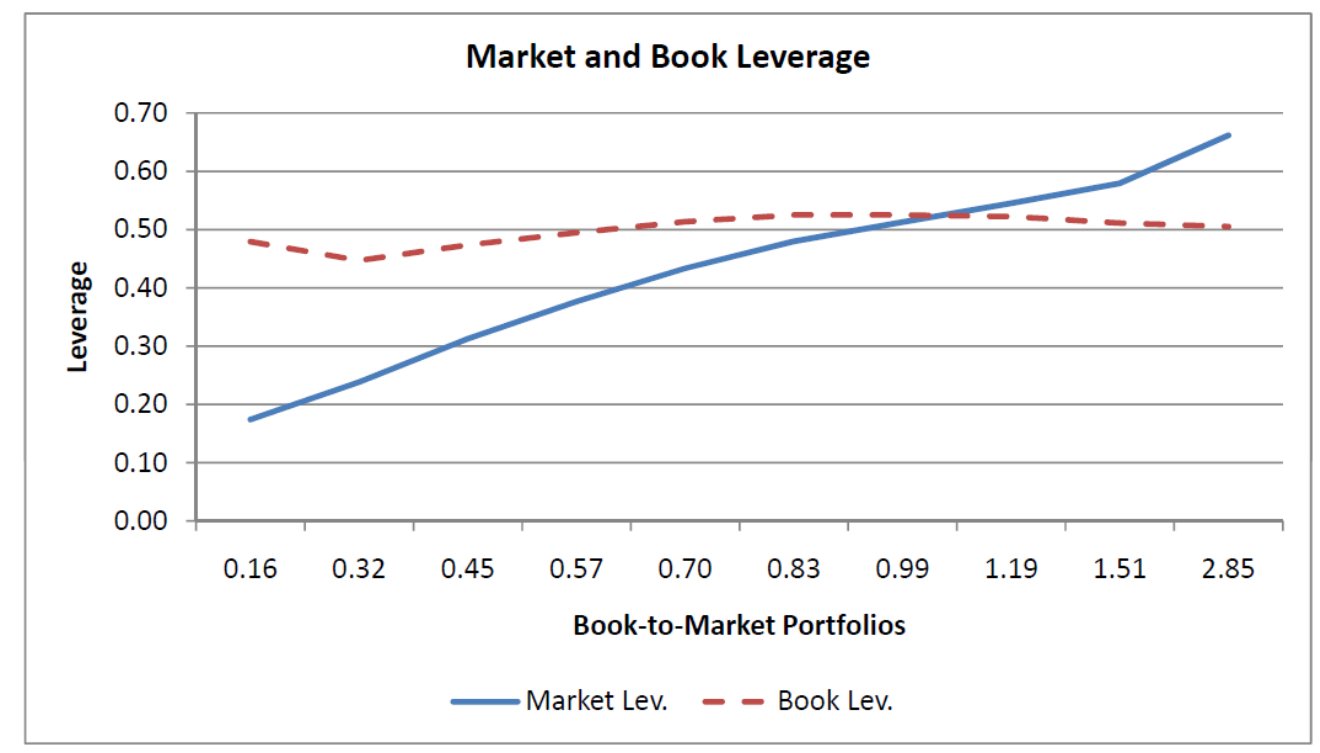

Figure 1: Book leverage and market leverage across different book-to-market value portfolios created using the method in Fama and French (1992). The numbers on the horizontal axis give the average book-to-market equity value in each portfolio. The numbers on the vertical axis give the average market and book leverage in each portfolio. Source: The Center for Research in Security Prices, CRSP-COMPUSTAT merged database, and author's calculations.

book and market leverage within different book-to-market portfolios and provides support for this argument. ${ }^{2}$ Moreover, because the level of debt is constant in the inaction region (when the firm does not invest) the firm's market debt-to-equity ratio varies closely with fluctuations in its own stock price. This implication of the model is in line with the results of Welch (2004), who finds that U.S. corporations do little to counteract the influence of stock price changes on their capital structures.

My analysis shows that the investment irreversibility alone causes a growth premium rather than a value premium. The firm's investment opportunity is a call option, because the firm has the right but not the obligation, to buy a unit of capital at a predetermined price. As we know from the financial options literature, when the price of the underlying security rises and falls, the price of the call option rises and falls at a greater rate. This suggests that the value of a growth option, that is, the call option to invest, should be more responsive to economic shocks than the assets-in-place. Therefore, growth options increase the riskiness of the firm. Similarly, the disinvestment opportunity is a put option, because

\footnotetext{
${ }^{2}$ This further supports the choice of risk-free debt over risky debt. In a tradeoff model, it is optimal for more productive firms to have greater book leverage, since debt is less costly for them, which would contradict the data.
} 
the firm has the right, but not the obligation, to sell a unit of capital at a predetermined price. The value of this put option is negatively related to the value of the underlying asset, because the gain from exercising it is higher for less productive firms. Therefore, the disinvestment option provides the value firms that have low productivity with insurance against downside risk and hence reduces their riskiness. This proposition is contrary to the wisdom of recent literature, for example, Zhang (2005) and Cooper (2006), which presents investment irreversibility as the source of the value premium.

In my model, financial leverage affects stock returns directly, through its effect on equity risk à la Modigliani and Miller (1958), and indirectly, through its effect on business risk, by influencing investment decisions. I find that these two channels have opposing effects on the relationship between book-to-market ratios and stock returns. However, the Modigliani-Miller effect strongly dominates the investment channel and explains the major share of the value premium.

The Modigliani-Miller (1958) effect of debt comes from the fact that the book-tomarket ratio and market leverage are closely related when book leverage is constant as we observe within the context of this model. In particular, if we let $B E, M E, B L$, and $M L$ be book value of equity, market value of equity, book leverage, and market leverage, respectively, and use the fact that the market value of debt is equal to the book value of debt when debt is risk-free, we have

$$
\frac{B E}{M E}=\frac{M L}{1-M L} \frac{1-B L}{B L} .
$$

Because book value is constant across value and growth firms, this equation implies that value firms have higher market leverage than growth firms. Therefore, they have greater equity risk according to the Modigliani and Miller theorem.

Financial leverage also affects investment and hence the business risk, because it influences the effective degree of investment irreversibility faced by the owners of the firm. When investment can be financed with leverage, the effective price of capital is reduced by the tax savings associated with debt financing at the time of investment. On the other hand, at the time of disinvestment, the firm has to pay back its debt, in line with the debt agreement and therefore has to give up the tax savings associated with the debt financing of that particular investment. Because the purchase price is greater than the resale price and both should be adjusted by the same value of tax savings, their ratio increases as a result of debt financing. This increases the effective irreversibility perceived by the owners of the firm. Since irreversibility reduces the value premium, so, too, does the investment channel of leverage. 
This paper is closely related to the growing literature that tries to link corporate decisions to asset returns. In addition to Zhang (2005) and Cooper (2006) discussed above, Carlson, Fisher, and Giammarino (2004) link the value premium to operating leverage. Livdan, Sapriza, and Zhang (2009) look at the effect of exogenous risk-free debt capacity on stock returns, and Gomes and Schmid (2009) link leverage and growth options to asset returns. The paper contributes to this literature in many ways. First, the closed-form solution of the model identifies explicitly how investment irreversibility, financial leverage, and their interaction affect the cross-section of stock returns. Second, the debt capacity of the firm is endogenously determined. Third, the paper does not need to rely on a high degree of irreversibility in order to generate a sizable variation in stock returns, because of the interaction of financial leverage and irreversibility $\left.\right|^{3}$ Fourth, the paper calibrates the model using maximum likelihood to capture the distribution of book-to-market values instead of plugging in parameter values in an ad hoc manner and the calibrated model captures the distribution of market leverage reasonably well. 45 Finally, the paper shows that financial leverage can explain the value premium.

The next section presents the problem of the firm in a continuous time setting. The third section then discusses the optimal investment policy and the market value of equity. The fourth section presents optimal financing policy and its relationship with investment. The fifth section links stock returns with investment irreversibility and financial leverage. The two sections thereafter present the calibration of the model and the comparison of simulation results with the data. The section thereafter provides an extension of the model, introducing the time varying-price of capital to account for the failure of the CAPM, and the last section concludes.

\section{The Model}

My model extends the investment irreversibility model of Abel and Eberly (1996) with corporate taxes, debt, and a stochastic discount factor to capture investors' risk preference. While debt capacity and investment and financing decisions are endogenous, investors'

\footnotetext{
${ }^{3}$ The degree of irreversibility assumed by the cited papers implies that the net value generated by disinvestment is non-positive after adjustment costs are included. However, Hall (2004) estimates the adjustment cost parameter for capital in a quadratic adjustment cost model without debt and finds that adjustment costs are relatively small and are not an important part of the explanation of the large movements in company values.

${ }^{4}$ To the best of my knowledge, no other paper in the literature makes an effort to match the distribution of book-to-market values and leverage, although this distribution is important in generating the cross-sectional distribution of returns. The implications of omitting this fact are crucial and are discussed in the Calibration section.
} 
preferences are captured by an exogenous discount factor, as in Zhang (2005), Cooper (2006), and Carlson, Fisher, and Giammarino (2004), among others.

The firms choose their investment and financing policy in order to maximize the market value of equity. Investment is subject to partial irreversibility, that is, the purchase price of one unit of capital is 1 and the resale price is $\eta<1$. Each firm produces output at time $t$ using capital, $K_{t}$, and takes the level of productivity, $X_{t}$, and the stochastic discount factor of investors, $S_{t}$, as exogenously given. Both $X_{t}$ and $S_{t}$ follow geometric Brownian motions

$$
\begin{aligned}
\frac{d X_{t}}{X_{t}} & =\mu_{X} d t+\sigma_{A} d w_{A}+\sigma_{i} d w_{i}=\mu_{X} d t+\sigma d w \\
\frac{d S_{t}}{S_{t}} & =-r d t-\sigma_{S} d w_{A}
\end{aligned}
$$

where $E_{t}\left[-d S_{t} / S_{t}\right]=r d t$ is the interest rate and $\sigma_{S}$ is the price of risk..$^{5}$ The Brownian increments $d w_{A}$ and $d w_{i}$ represent systematic and idiosyncratic shocks and are independent of each other. They can be aggregated using $\sigma=\sqrt{\sigma_{i}^{2}+\sigma_{A}^{2}}$ and $d w=\left(\sigma_{i} / \sigma\right) d w_{i}+$ $\left(\sigma_{A} / \sigma\right) d w_{A}$. Moreover, if we let $U_{t}$ and $L_{t}$ denote total capital purchases and total capital sales, respectively, up to time $t$, we can write the net change in the stock of capital as

$$
d K_{t}=d U_{t}-d L_{t}
$$

where $d U_{t} \geq 0$ and $d L_{t} \geq 0$.

The net income of the firm is given by the operating cash flows net of the cost of maintenance and cash flows to debtholders plus tax shields from depreciation and interest payments:

$$
\bar{\pi}\left(K_{t}, X_{t}, b_{t}\right)=(1-\tau)\left(\frac{h}{1-\gamma} X_{t}^{\gamma} K_{t}^{1-\gamma}-\delta K_{t}-r b_{t} K_{t}\right)
$$

where $\tau$ is the tax on corporate income, $h>0$ is the productivity multiplier, and $0<\gamma<1$ is the returns-to-scale parameter of the production function. ${ }^{6}$ On the cash outflow side, $\delta$ is the maintenance cost per unit of capital, $r$ is the risk-free rate on debt, and $b_{t}$ is the fraction of the capital provided by the lenders, or book leverage.

I model financial leverage as risk-free debt extended through a credit line where the

\footnotetext{
${ }^{5}$ This stochastic discount factor can be derived as the result of time-separable constant relative risk aversion utility with a constant discount rate, where consumption follows a geometric Brownian motion, or linear utility with a time-varying discount rate.

${ }^{6}$ This functional form nests a Cobb-Douglas production function with an isoelastic demand curve and a geometric Brownian motion technology process in which variable inputs, such as labor, have been optimized out.
} 
debtholders agree to finance a certain fraction of operating capital. Intuitively, the lenders can keep the debt risk-free by a collateralized debt agreement and can limit the amount of debt by the resale price of capital so that $\eta \geq b$. Alternatively, they can set a limit on debt that guarantees that the firm always has non-negative market equity and hence honors its debt rather than going bankrupt. The firm has the option to renegotiate this fraction later, but debt restructuring requires that the existing debt be retired altogether and that the new debt be issued at a cost proportional to the amount of new debt, $c$, as in Fisher, Heinkel, and Zechner (1989).

As a result of this credit line, the firm will invest when the marginal value of capital to equity holders is $1-b$, as this is the fraction of new investment that should be financed with equity. Moreover, the firm will disinvest when the marginal value of capital is $\eta-b$, because the firm gets $\eta$ for each unit of capital sold but has to give back $b$ to debtholders in order to keep the book leverage constant, in accord with the debt agreement. In the following analysis, $X_{U}(K, b)$ denotes the investment boundary along which the marginal value of capital is $1-b$, while $X_{L}(K, b)$ denotes the disinvestment boundary along which the marginal value of capital is $\eta-b$. These two boundaries enclose the inaction region where the marginal value of capital is between $1-b$ and $\eta-b$ and net investment is zero. This investment policy will be discussed in more detail in the next section.7

The following proposition establishes that the firm will never go bankrupt under a collateralized debt agreement.

Proposition 1 The market value of equity is strictly positive if debt is limited by the resale price of capital and the marginal value of capital is right-continuous at the investment boundary.

Proof. We have $\eta \geq b$ if debt is limited by the resale price of capital. The market value of equity is bounded by $(\eta-b) K \geq 0$, because this is what the shareholders will get after paying the lenders if they decide to dissolve the firm. Let $J(X, K, b)$ be the market value of equity and $K_{U}(X, b)$ be the inverse of the investment boundary $X_{U}(K, b)$ with respect to capital. Then $J\left(X, K_{U}(X, b), b\right)>(\eta-b) K$ must hold, since otherwise the firm would dissolve immediately, leaving the shareholders with capital $(\eta-b) K$ in return to their investment $(1-b) K$. Therefore, $J\left(X, K_{U}(X, b), b\right)>0$. Finally, we can write the market value of equity as

$$
J(X, K, b)=J\left(X, K_{U}(X, b), b\right)+\int_{K_{U}(X, b)}^{K} J_{K}(X, k, b) d k,
$$

\footnotetext{
${ }^{7}$ I assume that the accounting salvage value of the capital is the same as the actual salvage value, for the sake of simplicity so that the firm does not pay any taxes on resale price of capital.
} 
where $1-b \geq J_{K}(X, K, b) \geq(\eta-b) \geq 0$, because the marginal value of capital is bounded due to investment and disinvestment options. Moreover, $J_{K}\left(X, K_{U}(X, b), b\right)=$ $1-b>0$ because $b \leq \eta<1$. Because the marginal value of capital is right-continuous, this implies that $J_{K}(K, X, b)>0$ for values of $K$ arbitrarily close to $K_{U}(X, b)$. We also have $K \geq K_{U}(X, b)$ for any given $X$ and $b$, because the firm will invest to prevent the value of capital from falling below $K_{U}(X, b)$. Therefore, the integral on the right side of this equation should be positive. Since sum of the two positive terms is positive, we have $J(X, K, b)>(\eta-b) K \geq 0$, and this completes our proof.

This proposition essentially tells us that even if the firm had the option to go bankrupt, it would never exercise this option when debt is limited by the resale price of capital, because the disinvestment boundary would be hit before bankruptcy becomes optimal ${ }^{8}$ It follows immediately that the debt agreement with a no-bankruptcy condition is less restrictive. In particular, it should provide a greater debt limit because the market value of equity would still be non-negative if the lenders lent the firm more than the resale value of its capital. Since bankruptcy is suboptimal under both lending policies, I omit bankruptcy in the rest of the paper.

The firm maximizes shareholder value by choosing its investment and financing plans:

$$
\begin{aligned}
J\left(K_{t}, X_{t}, b_{t}\right)= & \max _{\left\{d U_{t+s}, d L_{t+s}, d b_{t+s}\right\}} \int_{0}^{\infty} \frac{S_{t+s}}{S_{t}}\left[\bar{\pi}_{t+s} d s-\left(1-b_{t+s}\right) d U_{t+s}+\left(\eta-b_{t+s}\right) d L_{t+s}\right] \\
& +\sum_{s \in\left\{s: d b_{t+s} \neq 0\right\}}^{\infty} \frac{S_{t+s}}{S_{t}}\left[d b_{t+s}-c\left(b_{t+s}+d b_{t+s}\right)\right] K_{t+s},
\end{aligned}
$$

where the term $d b_{t+s}$ is the change in book leverage after debt adjustment, and $\int_{0}^{\infty} d U_{t+s}$ and $\int_{0}^{\infty} d L_{t+s}$ are Stieltjes integrals. Note that the stochastic discount factor does not appear as a state variable in the value function $J$ because $S_{t+s} / S_{t}$ is log-normally distributed with parameters $r t$ and $\sigma_{S}^{2} t$ and this distribution does not depend on any state variable.

The debt limit imposed by the lenders adds an additional constraint to the problem. If debt is limited by the resale value of capital, then this constraint is simply $b_{t+s} \leq \eta .9$ If, on the other hand, debt is limited by the no-bankruptcy condition then we have

$$
0 \leq J\left(K_{t+s}, X_{t+s}, b_{t+s}\right) \text { for all } K_{t+s}, X_{t+s}, b_{t+s} .
$$

\footnotetext{
${ }^{8}$ Note that, in order to minimize the burden on the reader, the proof does not depend on any functional assumptions regarding the market value of equity and does not require modeling the bankruptcy option explicitly. However, the calculations for the firm with the bankruptcy option are available upon request.

${ }^{9}$ Although I have shown that the debt policy with the no-bankruptcy condition provides a greater debt capacity than the collateralized debt policy, I still cannot rule out the latter until I show that debt financing is preferred to equity financing, which I show in the next section.
} 
Because of investment and debt adjustment costs, it is not optimal for the firm to adjust capital and debt frequently. The Hamilton-Jacobi-Bellman equation (HJB) in the inaction region where the firm does not make any adjustments is given by

$$
r J(K, X, b)=\bar{\pi}(K, X, b)+\mu X J_{X}(K, X, b)+\frac{1}{2} \sigma^{2} X^{2} J_{X X}(K, X, b),
$$

where $\mu=\mu_{X}-\sigma_{S} \sigma_{A}$ is the risk-adjusted drift of the productivity process ${ }^{10}$ When we divide both sides of this equation by the market value of equity, $J$, this equation tells us that the required rate of return from buying the firm should be equal to the dividend yield (the first term) plus capital appreciation (the second and third terms).

The boundary conditions ${ }^{11}$ at the investment boundary, $X_{U}(K, b)$, are

$$
\begin{aligned}
J_{K}\left(K, X_{U}(K, b), b\right) & =1-b \\
J_{K K}\left(K, X_{U}(K, b), b\right) & =0 \\
J_{K X}\left(K, X_{U}(K, b), b\right) & =0 \\
J_{K b}\left(K, X_{U}(K, b), b\right) & =-1,
\end{aligned}
$$

while the boundary conditions at the disinvestment boundary, $X_{L}(K, b)$, are given by

$$
\begin{aligned}
J_{K}\left(K, X_{L}(K, b), b\right) & =\eta-b \\
J_{K K}\left(K, X_{L}(K, b), b\right) & =0 \\
J_{K X}\left(K, X_{L}(K, b), b\right) & =0 \\
J_{K b}\left(K, X_{L}(K, b), b\right) & =-1 .
\end{aligned}
$$

Finally, if we denote the book leverage after adjustment as $b^{\prime}$, the boundary conditions at the debt adjustment boundary are given by

$$
\begin{aligned}
J\left(K, X_{B}(K, b), b\right) & =J\left(K, X_{B}(K, b), b^{\prime}\right)+\left(b^{\prime}-b\right) K-c b^{\prime} K \\
J_{K}\left(K, X_{B}(K, b), b\right)-c b & =J_{K}\left(K, X_{B}(K, b), b^{\prime}\right)+\left(b^{\prime}-b\right)-c b^{\prime} \\
J_{X}\left(K, X_{B}(K, b), b\right) & =J_{X}\left(K, X_{B}(K, b), b^{\prime}\right) \\
J_{b}\left(K, X_{B}(K, b), b\right) & =-K \\
-(1-c) K & \leq J_{b}\left(K, X_{B}(K, b), b^{\prime}\right) .
\end{aligned}
$$

\footnotetext{
${ }^{10}$ This is essentially the same as substituting the stochastic discount factor with the risk-free rate and taking expectations under the risk-neutral measure.

${ }^{11}$ These conditions are known as value-matching and smooth pasting conditions that guarantee the continuity and optimality of the value function. Dixit (1993) is a good introduction for the derivation of these conditions.
} 
The last of these conditions is the first order condition with respect to after-adjustment leverage, $b^{\prime}$ under debt constraint. Hence it holds as an equality if the new book leverage satisfies $b^{\prime}<\eta$ or $J\left(K, X, b^{\prime}\right)>0$, depending on the constraint imposed by the lender. The market value of equity, $J(X, K, b)$, should be homogeneous of degree one in $K$ and $X$, because the cashflows and the adjustment costs on debt and investment are homogeneous in $K$ and $X 12$

\section{Optimal Investment Policy and the Valuation of Equity}

Since equation (1) holds identically in $K$, we can take the derivative of both sides with respect to $K$ to get

$$
r J_{K}(K, X, b)=\bar{\pi}_{K}(K, X, b)+\mu X J_{K X}(K, X, b)+\frac{1}{2} \sigma^{2} X^{2} J_{K X X}(K, X, b) .
$$

Because all terms in the firm's problem are homogeneous of degree one in $X$ and $K$, the value of the firm should also be homogeneous of degree one in $X$ and $K$. As a result, the marginal value of capital should be homogeneous of degree zero in $X$ and $K$. Therefore, we can define $y \equiv X / K$ and $q(y, b) \equiv J_{K}(K, X, b)$ to express the last equation as

$$
r q(y, b)=\bar{h} y^{\gamma}-\bar{m}+\mu y q_{y}(y, b)+\frac{1}{2} \sigma^{2} y^{2} q_{y y}(y, b)
$$

where $\bar{h}=(1-\tau) h$ and $\bar{m}(b)=(1-\tau)(\delta+r b)$ is the marginal cost of maintenance and financing. Then, the boundary conditions at the upper and lower investment bounds are given by the following equations..$^{13}$

$$
\begin{aligned}
& q\left(y_{L}(b), b\right)=\eta-b \text { and } q_{y}\left(y_{L}(b), b\right)=0 \\
& q\left(y_{U}(b), b\right)=1-b \text { and } q_{y}\left(y_{U}(b), b\right)=0 .
\end{aligned}
$$

This reduces the original HJB equation to an ordinary differential equation; solving this involves finding two constants of integration and the boundary values for $y$. Figure 2 displays the projection of the investment and inaction regions implied by the boundary conditions

\footnotetext{
${ }^{12}$ This argument is similar to the one in Abel and Eberly (1996) and Cooper (2006). To justify this homogeneity property and hence that $X / K$ is a sufficient statistic to describe the solution of the model, the reader can directly substitute in $V(y, b) \equiv V(X / K, b)=J(X, K, b) / K$ and see that both the HJB equation and the boundary conditions can be expressed in terms of $V(y, b)$ and its derivatives.

${ }^{13}$ We can see that the additional smooth pasting conditions for $b$, that is, $q_{b}\left(y_{L}(b), b\right)=q_{b}\left(y_{L}(b), b\right)=$ -1 are automatically satisfied once we take the derivative of the value-matching equations and apply the smooth pasting conditions for $y$. Therefore, we omit these conditions for the rest of the analysis.
} 


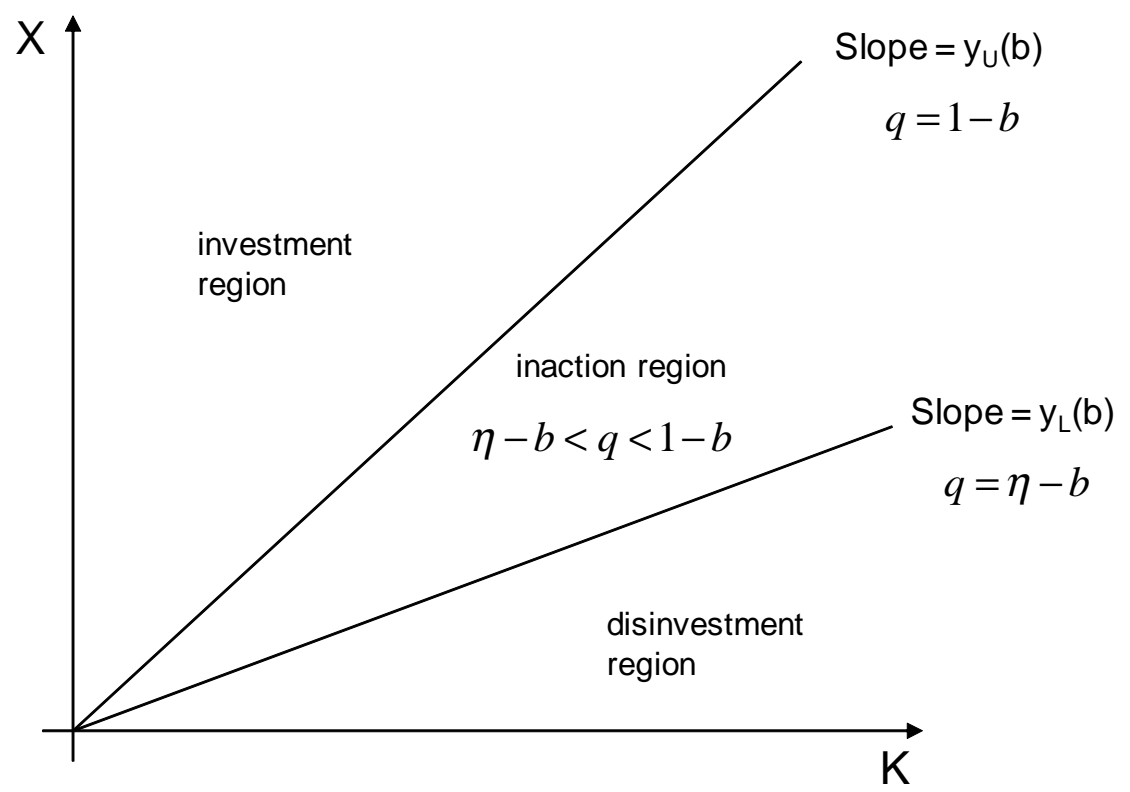

Figure 2: Projection of investment and inaction regions on the K-X plane. The line with slope $y_{U}(b)$ gives the investment boundary, while the line with slope $y_{L}(b)$ gives the disinvestment boundary. These two boundaries enclose the inaction region for investment. Source: Author's calculations.

on the $(K, X)$ plane.

The appendix shows that solving these equations and integrating the marginal value of capital leads to

$$
J(K, X, b)=\bar{H} X^{\gamma} K^{1-\gamma}+\bar{D}_{P}(b) X^{\alpha_{P}} K^{1-\alpha_{P}}+\bar{D}_{N}(b) X^{\alpha_{N}} K^{1-\alpha_{N}}-\frac{\bar{m}(b)}{r} K,
$$

where $\alpha_{P}>1>\gamma>0>\alpha_{N}, \bar{D}_{P}(b)$, and $\bar{D}_{N}(b)$ are functions of book leverage that take only positive values ${ }^{14}$ The four terms are the value of assets in place (before costs), growth options, disinvestment options, and the present value of operating and financing costs.

\section{Financial Leverage and Investment}

We now turn our attention to optimal financing policy and its relationship with investment. The following proposition shows that the tax advantage of leverage makes the firm choose its investment policy as if it faced greater irreversibility. Then I will show that the optimal

\footnotetext{
${ }^{14}$ Note that the derivation of the market value of equity does not make use of the boundary conditions for debt restructuring.
} 
financing policy for the firm is to exhaust its debt capacity. Therefore, the firm prefers the no-bankruptcy condition because it provides greater debt capacity. Finally, I show that the debt capacity under the no-bankruptcy condition is independent of state variables.

Proposition 2 When interest payments are tax deductible, the gap between the investment boundary and the disinvestment boundary as measured by $G(b) \equiv y_{U}(b) / y_{L}(b)$ increases with book leverage $b$.

\section{Proof. See appendix}

Intuitively, the gap between the investment and disinvestment boundaries increases as the ratio of the purchase to the resale price increases, because it is this discrepancy between prices that creates investment irreversibility. Then, we should answer why the purchase price increases relative to the resale price. When investment is financed with leverage, the shareholders care not only about the actual price of capital but also about the financing costs. At the time of investment, the net purchase price of capital from the shareholders' perspective is the actual price net of any tax savings due to debt financing. At the time of disinvestment, the net resale price of capital is the actual price minus the loss of tax deductions due to debt repayment. Since the purchase and resale prices of capital increase by the same amount of tax savings, their ratio should increase. This increases the effective irreversibility perceived by the shareholders.

The next two propositions show that the optimal behavior for the firm is to use all of its debt capacity at once if the cost of issuing debt is sufficiently small so that the tax savings due to interest payments dominate the cost of debt financing and never to adjust its book leverage after that. I assume that the cost of issuing debt is below this limit.

Proposition 3 Let $G(b) \equiv y_{U}(b) / y_{L}(b)>1$. Then, there is a critical level for the cost of issuing debt, given by

$$
c^{*}=\tau\left(1-\frac{1}{1-\alpha_{N}}\right)>0
$$

below which the firm strictly prefers debt to equity.

Proof. See appendix

Proposition 4 It is never optimal to readjust debt.

Proof. The appendix shows that $J_{b}(X, K, b)+K \geq 0$. Therefore, the smooth pasting conditions required at the disinvestment boundary are not satisfied.

The following proposition shows that the leverage limit set by the debtholders is the same for all firms regardless of their productivity and capital levels. 
Proposition 5 The debt limit implied by the no-bankruptcy condition is not state-dependent.

Proof. Using equation (5) we can write the no-bankruptcy condition $J(K, X, b) \geq 0$ as $J(K, X, b) / K=J(1, y, b) \geq 0$, that is

$$
J(1, y, b)=H y^{\gamma}+D_{P}(b) y^{\alpha_{P}}+D_{N}(b) y^{\alpha_{N}}-\frac{\bar{m}}{r} \geq 0 .
$$

Moreover, $J(1, y, b)$ should be increasing in $y$ because, given capital and leverage, more productive firms should have higher market value, that is, $J_{X}(K, X, b)>0$. Therefore, $J(K, X, b) \geq 0$ for all $(X, K, b)$ if and only if $J\left(1, y_{L}(b), b\right) \geq 0$. As a result, the debt limit is given by the equation $J\left(1, y_{L}(b), b\right)=0$, whose solution is independent of state variables.

This proposition tells us that the book leverage in this model should not be statedependent because the debt limit is determined by the worst-case scenario, which is also not state-dependent due to the homogeneity of the firm's value. This result is important for two reasons: First, it strengthens the result that it is not optimal to adjust debt once it is set because it is costly to adjust and the new limit would be the same as the old one. Second, because the debt limit as a fraction of total capital is the same for all firms, book leverage is the same across firms with different book-to-market ratios. Figure 1 shows that this implication of the model fits the data.

\section{Stock Returns}

\subsection{Investment Irreversibility and Stock Returns}

In order to isolate the pure effect of investment irreversibility of stock returns, I focus on a firm that does not have any operating costs and financial leverage. In this case, the market value of firm's equity is given by

$$
J(K, X)=H X^{\gamma} K^{1-\gamma}+D_{P} X^{\alpha_{P}} K^{1-\alpha_{P}}+D_{N} X^{\alpha_{N}} K^{1-\alpha_{N}},
$$

where $\alpha_{P}>1>\gamma>0>\alpha_{N}$ and $H, D_{P}$, and $D_{N}$ are positive constants. These three terms capture market value of the assets-in-place, the growth options, and the disinvestment options, which I denote $J^{A P}, J^{G}$, and $J^{D}$ respectively.

Using Ito calculus and some algebra we can derive the (conditional) expected excess 
stock return as

$$
\begin{aligned}
\frac{1}{d t} E(d R)-r & =\frac{1}{d t} E\left(\frac{\pi d t+d J}{J}\right)-r=\sigma_{S} \sigma_{A} \frac{J_{X} X}{J} \\
& =\sigma_{S} \sigma_{A}\left(\frac{J^{A P}}{J} \gamma+\frac{J^{G}}{J} \alpha_{P}+\frac{J^{D}}{J} \alpha_{N}\right) \\
& =\sigma_{S} \sigma_{A}\left(s_{A P} \gamma+s_{G} \alpha_{P}+s_{D} \alpha_{N}\right) .
\end{aligned}
$$

Therefore, the excess stock return is a value-weighted average of excess returns that come from the three sources of value. Since the book-to-market ratio can be expressed as $K / J(K, X)=$ $1 / J(1, y)$, the ratio of productivity to capital is a sufficient statistic that is negatively related to the book-to-market ratio. It is then straightforward to show that the stock return increases in $y$ and hence decreases in book-to-market values, producing a growth premium rather than a value premium. ${ }^{15}$

The result presented in this section is intuitive, once we realize the similarities of growth and disinvestment options with financial options. The firm's investment opportunity is a call option because the firm has the right, but not the obligation, to buy a unit of capital at a predetermined price. As we know from the financial options literature, as the price of the underlying security rises and falls, the price of the call option rises and falls at a greater rate than the underlying security..$^{16}$ This suggests that the value of the growth option, that is, the call option to invest, should be more responsive to profitability shocks, and hence riskier, than the assets-in-place. This is captured by $\alpha_{P}>\gamma$ in this model. As a result, growth firms, which derive their value mainly from growth options should have higher expected returns than value firms.

Similarly, the disinvestment opportunity is a put option, because the firm has the right, but not the obligation, to sell a unit of capital at a predetermined price. The value of this put option is negatively related to the value of the underlying asset, because the gain from exercising the option, that is, disinvestment, is higher for less productive firms. Therefore, the disinvestment option provides the value firms with insurance against downside risk and hence reduces their riskiness. In this model, this is captured via $\alpha_{N}<0$.

This result is in contrast with the intuition of several recent papers, such as Zhang (2005) and Cooper (2006), that present investment irreversibility as the source of the value premium. These papers argue that investment adjustment costs make it harder for value

\footnotetext{
${ }^{15}$ Intuitively, the assets-in-place and growth options build a higher fraction of market value for firms with a higher productivity-to-capital ratio. This fact, combined with the arithmetic signs of the parameters, leads to a positive derivative of stock returns with respect to $y$. The appendix provides the calculus.

${ }^{16}$ The call option is implicitly leveraged: If we denote the underlying security price with $S$ and the strike price with $K$, the payoff of the call options is $\mathrm{S}-\mathrm{K}$, which has the elasticity $d \ln (S-K) / d \ln S>1$, where the strike price, $K$, is the leverage.
} 
firms to deploy their excess capital when the economy faces bad shocks, whereas growth firms do not face the same problem, as they do not have too much excess capital. As a result, assets-in-place should be riskier than growth options and hence value firms should be riskier than growth firms. However, these papers include fixed operating costs in the profit function of the firm, which would affect the business risk, possibly creating a value premium as Carlson, Fisher, and Giammarino (2004) suggest. Unfortunately, these papers do not provide an analysis of how much of the difference in returns is accounted for by the irreversibility and operating leverage ${ }^{17}$

The following proposition generalizes the argument that growth options are riskier than assets-in-place, by providing a proof that does not depend on the properties of the adjustment cost or of the processes for productivity or the stochastic discount factor. The proposition focuses on total irreversibility of investment because, if the irreversibility were the main reason for value premium, it should create the greatest value premium if firms were not able to disinvest.

Proposition 6 In the absence of leverage and under perfect investment irreversibility, growth options are riskier than assets-in-place.

Proof. In case of perfect irreversibility the firm does not have a disinvestment option. Therefore, the market value of equity consists of value of growth options and assets-inplace only. If we let $r_{A P}$ be the return on assets in place and $r_{G}$ be the return on the growth option, we can write the expected returns to equity as

$$
r_{E}=\frac{J^{A P}(K, X)}{J(K, X)} r_{A P}+\frac{J^{G}(K, X)}{J(K, X)} r_{G},
$$

where

$$
\begin{aligned}
J(K, X) & =J^{A P}(K, X)+J^{G}(K, X) \\
r_{E} & =\frac{J_{X}}{J}\left|\operatorname{cov}\left(d X, \frac{d S}{S}\right)\right| \\
r_{A P} & =\frac{J_{X}^{A P}}{J^{A P}}\left|\operatorname{cov}\left(d X, \frac{d S}{S}\right)\right| \\
r_{G} & =\frac{J_{X}^{G}}{J^{G}}\left|\operatorname{cov}\left(d X, \frac{d S}{S}\right)\right| .
\end{aligned}
$$

\footnotetext{
${ }^{17}$ Zhang (2005) provides (in Table IV) a sensitivity analysis that shows that a 10 percent reduction in fixed costs reduces the difference between stock returns of the firms in the highest and lowest book deciles by 1 percent. Unfortunately, there is no analysis about how the model performs when the fixed costs are set to zero. However, if we assume that the elasticity of return differences to fixed costs is constant, eliminating operating leverage should lead to a 10 percent decrease in the value premium between highest and lowest deciles and hence nullify the stock return differences.
} 
Moreover, given capital, firms with higher productivity have lower book-to-market values, and hence are growth firms, for which the growth options constitute a greater share of market value. Therefore, we should have

$$
\frac{\partial J^{G}(K, X) / J(K, X)}{\partial X}>0
$$

With a little algebra, we can show that

$$
\frac{\partial J^{G}(K, X) / J(K, X)}{\partial X}=\frac{J^{G}(K, X) / J(K, X)}{\left|\operatorname{cov}\left(d X, \frac{d S}{S}\right)\right|}\left(r_{G}-r_{E}\right),
$$

which together with previous inequality implies that $r_{G}>r_{E}>r_{A P}$. Therefore, growth options are risker than assets-in-place.

It follows, from this proposition, that growth firms that derive their value from growth options should have higher expected returns so that we have a growth premium rather than a value premium under investment irreversibility without leverage.

Despite the negative relationship of value premium and investment irreversibility, I keep irreversibility in my model because it is useful to generate a wide range of book-to-market values, and market leverage, and hence variation in stock returns. In particular, note that in the absence of irreversibility, the excess returns would be the same for all firms and equal to $\sigma_{S} \sigma_{A}$.

\subsection{Financial Leverage and Stock Returns}

Using Ito calculus and the Hamilton-Jacobi-Bellman equation (1) from the previous section, we can write the excess stock returns as

$d R_{i}-r d t=\frac{\bar{\pi}\left(K_{i}, X_{i}\right) d t+d J\left(K_{i}, X_{i}\right)}{J\left(K_{i}, X_{i}\right)}-r d t=\sigma_{S} \sigma_{A} \frac{X_{i} J_{i X}\left(K_{i}, X_{i}\right)}{J_{i}\left(K_{i}, X_{i}\right)} d t+\frac{X_{i} J_{i X}\left(K_{i}, X_{i}\right)}{J_{i}\left(K_{i}, X_{i}\right)} \sigma d w$,

where $\sigma_{S}$ is the price of risk, $\sigma_{A} \frac{X_{i} J_{i X}\left(K_{i}, X_{i}\right)}{J_{i}}$ is the risk exposure, and $\sigma d w=\sigma_{A} d w_{A}+$ $\sigma_{i} d w_{i}$. The appendix shows that we can rewrite excess stock returns as

$$
\frac{1}{d t} E\left(d R_{i}\right)-r=\left(1+\frac{\bar{m}(b) / r K}{J}\right)\left(\gamma s_{A P}+\alpha_{P} s_{G}+\alpha_{N} s_{D}\right) \sigma_{S} \sigma_{A}
$$

where the first factor captures the Modigliani-Miller effect, and the second factor decomposes the total business risk (as if the firm were all equity financed) into assets-in-place, a growth option, and a disinvestment option. 
Financial leverage affects returns in two ways. The first effect, the Modigliani-Miller channel, is obvious in equation (7). Firms with higher market leverage, $b K / J$, also have higher book-to-market values, $(1-b) K / J$, when book leverage, $b$, is constant. This makes the equity of firms with higher book-to-market value riskier.

The second effect comes from the interaction of financial leverage and investment. We have seen that financial leverage increases the effective degree of irreversibility faced by the owners of the firm and that irreversibility causes a growth premium, rather than a value premium. Therefore, the effect of leverage on business risk, which is captured by the second factor in equation (7), counteracts the Modigliani and Miller effect.

The net effect of leverage on stock returns depends on the parameterization of the model, which we will focus on next.

\section{Calibration}

Some parameters of the model have direct counterparts in the data. Accordingly, the tax rate is taken to be 35 percent from Taylor (2003). The risk-free rate is taken to be 2 percent, using a time series average of Fama's monthly T-bill returns from the CRSP database from 1963 to 2007 . The yearly value of $\sigma_{S}$ is set to 0.11 in order to match the average monthly Sharpe ratio of the excess market return, using the excess market return series from Kenneth French's webpage, again from 1963 to 2007. Finally, the book leverage is set equal to 0.5018

The remaining parameters for which we do not have direct observations are estimated via maximum likelihood, using the long-run stationary distribution of the book-to-market values from Compustat. I could calibrate all the parameters using a collection of numbers from other papers such as Zhang (2005), Cooper (2006), or Gomes and Schmid (2009), or I could estimate the parameters that fit the distribution of returns, as in Carlson, Fisher, and Giammarino (2004). Instead I make use of the distribution of book-to-market values, because explaining the cross-section of returns consists of two important steps: getting the relationship between returns and book-to-market values right and getting getting the distribution of book-to-market values right. If the model fails any of these steps, it cannot produce the correct distribution of returns. Even worse, a model can claim to explain the cross-section of returns correctly although it fails in both steps. Therefore, starting the analysis with the distribution of the book-to-market values provides a consistency check.

\footnotetext{
${ }^{18}$ Because of the interaction between resale price of capital and book leverage, it is enough to preset only one of these parameters. Since there is no consensus regarding the exact value of the resale price of capital, whereas we actually observe the book values from Compustat, I preset book leverage and estimate the implied resale value of capital.
} 


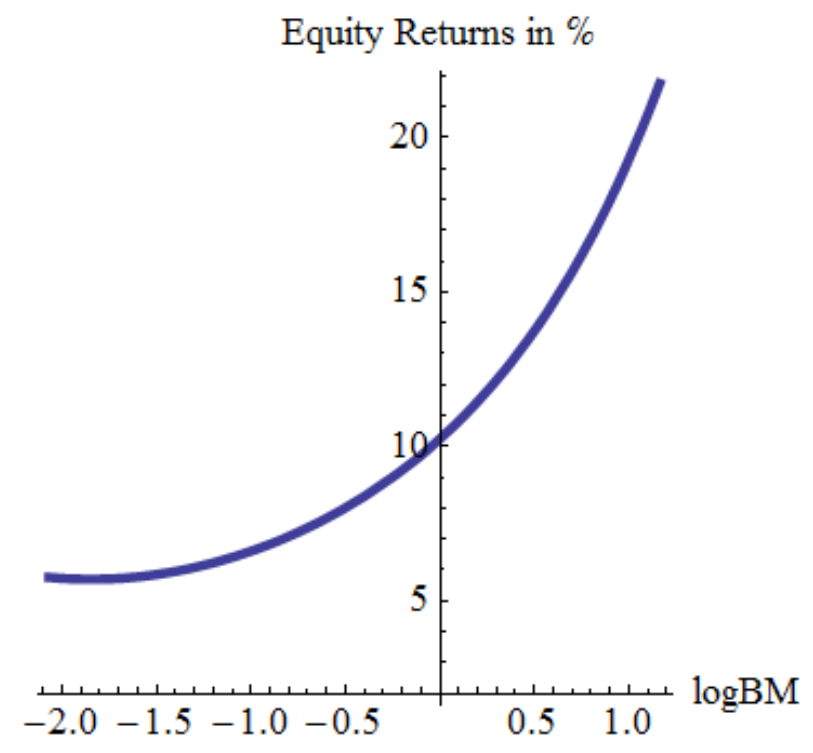

Figure 3: Expected returns vs. book-to-market ratio using the estimated parameters. Source: Author's calculations

\begin{tabular}{|lllllllll|}
\hline$r$ & $\sigma_{S}$ & $\mu_{X}$ & $\sigma_{A}$ & $\sigma_{i}$ & $\gamma$ & $\eta$ & $\tau$ & $\delta$ \\
0.02 & 0.38 & -0.028 & 0.05 & 0.15 & 0.20 & 0.40 & 0.35 & 0.07 \\
\hline
\end{tabular}

Table 1: Calibration of model parameters. Source: Author's calculations.

The appendix shows the derivation of the closed-form solution for the long-run stationary distribution of book-to-market values implied by the model. For estimation purposes, I make the counterfactual assumption that book-to-market values are serially and crosssectionally independent and identically distributed, because the complex nature of the full information maximum likelihood function would require resorting to simulated maximum likelihood, which would be computationally expensive. Hayashi (2000) shows that the resulting quasi-maximum likelihood estimator is indeed consistent, and it is a safe approach, given the high number of firm-year observations in Compustat.

The resulting estimation values are presented in Table 1, while Figure 3 gives the relationship between conditional expected stock returns and the book-to-market values implied by the calibration. The standard errors are to be calculated using a bootstrap procedure and ignored for now. Indeed, we see that the Modigliani and Miller channel of leverage dominates the investment channel, because the equity returns are increasing in book-to-market values.

Using this calibration we can also immediately decompose the contribution of leverage to stock returns through investment and Modigliani-Miller channels. Figure 4 shows that introducing debt has hardly any effect on business risk; hence the Modigliani-Miller 


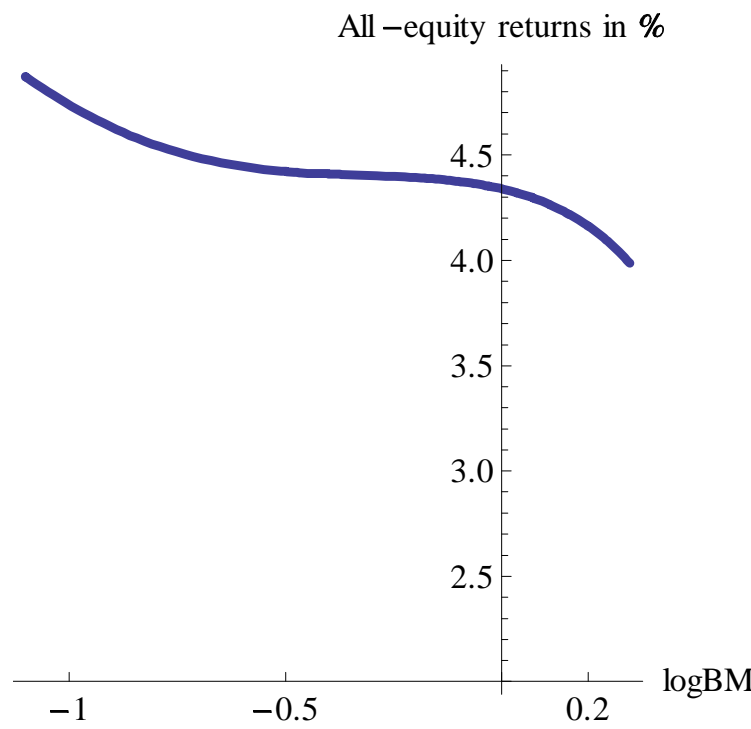

Total Firm Returns with Debt in \%

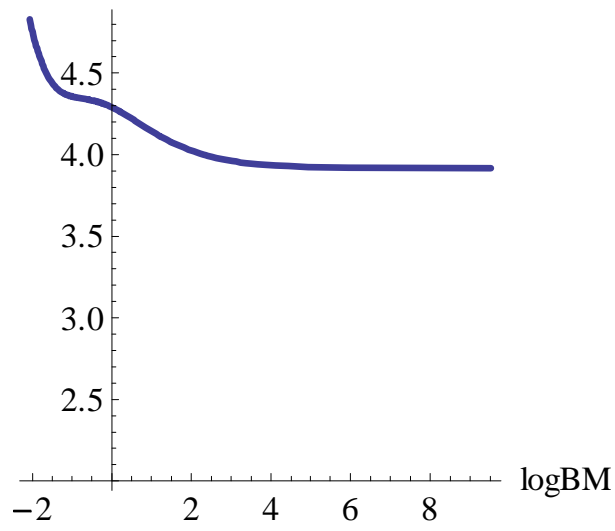

Figure 4: Total yearly expected firm returns, debt and equity combined, for the all-equity firm returns and leveraged firm returns. Source: Author's calculations

channel easily dominates the investment channel, as has been confirmed by Figure 3 .

\section{Simulation Results}

Using the parameter values in Table 1, I simulate the model to obtain the statistics for various book-to-market portfolios à la Fama and French (1992). Table 2 presents the simulation results and the statistics obtained from the Compustat and CRSP data for the July 1963-June 2008 period.

This table shows that the simulated returns, book-to-market ratios, and market leverage are very close to the data, in accordance with the intuition presented in the paper: when book-to-market values are relatively constant across different portfolios, value firms have higher leverage than growth firms, hence investing in the equity of value firms is riskier than investing in the equity of growth firms.

Finally and not surprisingly, because this is a single factor model, the Capital Asset Pricing Model (CAPM) $\beta$ s explain a significant part of the variation in stock returns (not reported here). This issue is addressed in the next section. 


\begin{tabular}{|r|c|c|c|c|c|c|c|c|}
\hline & \multicolumn{4}{|c|}{ Data } & \multicolumn{4}{c|}{ Model } \\
\hline Portfolio & Return & BE/ME & ML. & BL. & Return & BE/ME & ML. & BL. \\
\hline 1 & 8.48 & 0.16 & 0.17 & 0.48 & 9.48 & 0.19 & 0.14 & 0.50 \\
\hline 2 & 10.61 & 0.32 & 0.24 & 0.45 & 11.44 & 0.37 & 0.24 & 0.50 \\
\hline 3 & 12.14 & 0.45 & 0.31 & 0.47 & 12.38 & 0.53 & 0.31 & 0.50 \\
\hline 4 & 12.51 & 0.57 & 0.38 & 0.49 & 12.64 & 0.58 & 0.36 & 0.50 \\
\hline 5 & 14.12 & 0.70 & 0.43 & 0.51 & 14.68 & 0.83 & 0.41 & 0.50 \\
\hline 6 & 15.51 & 0.83 & 0.48 & 0.53 & 15.26 & 0.86 & 0.45 & 0.50 \\
\hline 7 & 17.14 & 0.99 & 0.51 & 0.52 & 17.96 & 1.19 & 0.50 & 0.50 \\
\hline 8 & 17.72 & 1.19 & 0.55 & 0.52 & 18.06 & 1.36 & 0.54 & 0.50 \\
\hline 9 & 19.93 & 1.51 & 0.58 & 0.51 & 20.30 & 1.53 & 0.60 & 0.50 \\
\hline 10 & 24.27 & 2.85 & 0.66 & 0.51 & 28.56 & 3.29 & 0.74 & 0.50 \\
\hline
\end{tabular}

Table 2: Data versus simulation results with estimated parameters. The simulation results are the average of 25 simulations with 4000 firms and 2500 periods each. The first 1500 periods have been discarded to allow the system to converge to its steady state. The portfolios are sorted according to their book-to-market values in order to form 10 portfolios every month, as done by Cooper (2006), instead of every year, as in Fama and French (1992). Yearly sorting does not change the results in a significant way. The results are averages across simulations. Simulated returns are adjusted upwards for inflation. Source: CRSP and Compustat merged database and author's calculations.

\section{Time-Varying Price of Capital}

One property of the model is that there is only a single systematic shock, and hence the conditional CAPM holds. Although the unconditional version of the CAPM cannot explain perfectly the differences in stock returns, it still explains a significant fraction - more than what is predicted by the data. This is a common property of the production-based models that try to explain cross-sectional variation in stock returns with only one shock ${ }^{19}$ However, one reason the value premium is a puzzle is that it cannot be explained by the CAPM. Many investor-based models like the inter-temporal capital asset pricing model (ICAPM), as studied by Merton (1973), Campbell and Vuolteenaho (2004), and Lettau and Wachter (2007), suggest that the CAPM fails because it does not price a risk factor correctly-in particular the shocks to discount rate.

Following their footsteps, in order to facilitate the violation of the conditional CAPM, this section introduces an additional systematic shock. In my case, this shock affects prices of capital goods. I show that this extended model can be reduced to a version of the original model where the CAPM does not capture correctly the risk prices for capital goods price

\footnotetext{
${ }^{19}$ Examples are Carlson, Fisher, and Giammarino (2004), Zhang (2005) and Berk, Green, and Naik (1999), among others.
} 
and productivity risk. As a result, the conditional CAPM betas do not line up with crosssectional stock returns and, even more interestingly, conditional betas may be negatively related to book-to-market ratios in some periods.

I assume that the price of capital follows a geometric Brownian motion, ${ }^{20}$ that is,

$$
\frac{d P_{t}}{P_{t}}=\mu_{P} d t+\sigma_{P} d w_{P}
$$

For this process, $\mu_{P}<0$ implies that increasing the capacity becomes cheaper over time, creating a vintage capital effect. We can write the problem of the firm as

$$
\begin{aligned}
W\left(K_{t}, \hat{X}_{t}, P_{t}\right)= & \max _{\left\{d U_{t+s}, d L_{t+s}, d b_{t+s}\right\}} E_{t} \int \frac{S_{t+s}}{S_{t}} \Pi\left(K_{t+s}, \hat{X}_{t+s}, P_{t+s}\right) d s \\
& +\int \frac{S_{t+s}}{S_{t}}\left[(1-b) P_{t+s} d U_{t+s}+(\eta-b) P_{t+s} d L_{t+s}\right] \\
& +\sum_{s \in\left\{s: d b_{t+s} \neq 0\right\}}^{\infty} \frac{S_{t+s}}{S_{t}}\left[d b_{t+s}-c\left(b_{t+s}+d b_{t+s}\right)\right] P_{t+s} K_{t+s}
\end{aligned}
$$

subject to

$$
\begin{aligned}
d K_{t} & =d U_{t}-d L_{t} \\
\frac{d S_{t}}{S_{t}} & =-r d t-\sigma_{S A} d w_{A, t}+\sigma_{S P} d w_{P, t} \\
\frac{d \hat{X}_{t}}{\hat{X}_{t}} & =\mu_{A} d t+\sigma_{A} d w_{A, t}+\sigma_{i} d w_{i, t} \\
\frac{d P_{t}}{P_{t}} & =\mu_{P} d t+\sigma_{P} d w_{P}
\end{aligned}
$$

where

$$
\Pi\left(K_{t}, \hat{X}_{t}, P_{t}\right) \equiv(1-\tau)\left(\frac{h}{1-\gamma} \hat{X}_{t} K_{t}^{1-\gamma}-\delta P_{t} K_{t}-r b P_{t} K_{t}\right)+\hat{\mu}_{P} b P_{t} K_{t} .
$$

The new term $\hat{\mu}_{P} b P_{t} K_{t}$ appears because of the changes in the amount of debt as a result of changes in the price of capital, where $\hat{\mu}_{P}=\mu_{P}+\sigma_{S P} \sigma_{P}$ is the risk-adjusted drift of the price process. Intuitively, operating capital acts as an asset that provides an instantaneous return of $d P / P$ as a result of the debt agreement and price movements and $\hat{\mu}_{P}$ is the riskadjusted value of this return. I assume that the risk prices of $\hat{X}$ and $P$ have opposite signs, because good times are characterized by higher productivity and lower input prices.

\footnotetext{
${ }^{20}$ For example, this process may come from a perfectly competitive industry that produces capital goods, with a linear production function subject to technology shocks that follow a geometric Brownian motion.
} 
Note that this problem is linearly homogeneous in $\hat{X}_{t}$ and $P_{t}$, since both variables follow a geometric Brownian motion and enter linearly into the problem. Therefore, I can divide everything by $P_{t}$ and define $X_{t}^{\gamma} \equiv \hat{X} / P_{t}, \pi(K, X) \equiv \Pi(K, \hat{X}, P) / P$ and $J(K, X) \equiv W(K, \hat{X}, P) / P$. This will give us the following Hamilton-Jacobi-Bellman equation in the inaction region

$$
\left(r-\hat{\mu}_{P}\right) J=\pi(K, X)+\mu X J_{X}+\frac{1}{2} \sigma^{2} X^{2} J_{X X}
$$

where

$$
\begin{aligned}
\mu & =\frac{1}{\gamma}\left(\hat{\mu}_{A}-\hat{\mu}_{P}\right)+\frac{1}{2}\left(\frac{1}{\gamma}-1\right) \frac{1}{\gamma}\left(\sigma_{P}^{2}+\sigma_{A}^{2}+\sigma_{i}^{2}\right) \\
\sigma^{2} & =\frac{1}{\gamma^{2}}\left(\sigma_{P}^{2}+\sigma_{A}^{2}+\sigma_{i}^{2}\right)
\end{aligned}
$$

with $\hat{\mu}_{A}=\mu_{P}-\sigma_{S A} \sigma_{A}$. This HJB equation is very similar to the HJB in the original model, and the boundary conditions are identical. As a result of this close relationship with the original model, all the analysis for the original model holds for this extended version. In particular, any investment and financing policy, distribution of book-to-market values, and stock returns under the original model can be replicated under the extended version. However, the behavior of the conditional CAPM will change significantly. We will focus on this in the next sections.

\subsection{Stock Returns}

In this section I provide the expressions of individual stock returns, denoted by $i$, and of the value-weighted market return in order to analyze the relationship of actual conditional expected returns with those implied by the CAPM. Let us define $G=W / S$ as the value of the firm. It can be shown that the equity returns in this extended version are given by

$$
\begin{aligned}
d R_{i}= & \left(r+\sigma_{S A} \sigma_{A} \frac{G_{i A} A_{i}}{G_{i}}-\sigma_{S P} \sigma_{P} \frac{G_{i P} P}{G_{i}}\right) d t \\
& +\frac{G_{i A} A_{i}}{G_{i}}\left(\sigma_{A} d w_{A}+\sigma_{i} d w_{i}\right)+\frac{G_{i P} P}{G_{i}} \sigma_{P} d w_{P}
\end{aligned}
$$


Due the homogeneity of $G(K, A, P)$ in $A$ and $P$, we have $\frac{G_{i P} P}{G_{i}}=\left(1-\frac{G_{i A} A_{i}}{G_{i}}\right)$. Using this and the definition of $J$, we can write the last equation as

$$
\begin{aligned}
d R_{i}= & {\left[r+\sigma_{S A} \sigma_{A} \frac{J_{i X} X_{i}}{\gamma J_{i}}-\sigma_{S P} \sigma_{P}\left(1-\frac{J_{i X} X_{i}}{\gamma J_{i}}\right)\right] d t } \\
& +\frac{J_{i X} X_{i}}{\gamma J_{i}}\left(\sigma_{A} d w_{A}+\sigma_{i} d w_{i}\right)+\left(1-\frac{J_{i X} X_{i}}{\gamma J_{i}}\right) \sigma_{P} d w_{P}
\end{aligned}
$$

Note that, similar to the original model, the effect of book-to-market value is captured by the elasticity of the market value of equity with respect to productivity shocks $J_{i X} X_{i} / J_{i}$.

Using individual stock returns, we can derive the market return as

$$
\begin{aligned}
d R_{m}= & {\left[r+\sigma_{S A} \sigma_{A} \frac{\int_{i} X_{i} J_{i X}\left(K_{i}, X_{i}\right) d i}{\gamma \int_{i} J_{i}\left(K_{i}, X_{i}\right) d i}-\sigma_{S P} \sigma_{P}\left(1-\frac{\int_{i} X_{i} J_{i X}\left(K_{i}, X_{i}\right) d i}{\gamma \int_{i} J_{i}\left(K_{i}, X_{i}\right) d i}\right)\right] d t } \\
& +\frac{\int_{i} X_{i} J_{i X}\left(K_{i}, X_{i}\right) d i}{\gamma \int_{i} J_{i}\left(K_{i}, X_{i}\right) d i} \sigma_{A} d w_{A}+\left(1-\frac{\int_{i} X_{i} J_{i X}\left(K_{i}, X_{i}\right) d i}{\gamma \int_{i} J_{i}\left(K_{i}, X_{i}\right) d i}\right) \sigma_{P} d w_{P} .
\end{aligned}
$$

\subsection{Market Beta and Failure of the Conditional CAPM}

Using the individual firm and value-weighted market returns presented above, I will show the failure of the conditional CAPM. For the sake of simplifying the notation, define

$$
\begin{aligned}
\Delta_{m} & =\frac{\int_{i} X_{i} J_{i X}\left(K_{i}, X_{i}\right) d i}{\gamma \int_{i} J_{i}\left(K_{i}, X_{i}\right) d i} \\
\Delta_{i} & =\frac{J_{i X} X_{i}}{\gamma J_{i}}
\end{aligned}
$$

Using the formulas above, we can calculate the conditional market beta as

$$
\begin{aligned}
\beta_{i} & =\frac{\operatorname{cov}\left(d R_{m}, d R_{i}\right)}{\operatorname{var}\left(d R_{m}\right)} \\
& =\frac{\Delta_{i} \Delta_{m} \sigma_{A}^{2}+\left(1-\Delta_{i}\right)\left(1-\Delta_{m}\right) \sigma_{P}^{2}}{\Delta_{m}^{2} \sigma_{A}^{2}+\left(1-\Delta_{m}\right)^{2} \sigma_{P}^{2}}
\end{aligned}
$$

Then, the expected instantaneous return implied by the conditional CAPM is not equal to conditional expected returns, that is,

$$
\begin{aligned}
\beta_{i} E\left[d R_{m}-r d t\right] & =\frac{\Delta_{i} \Delta_{m} \sigma_{A}^{2}+\left(1-\Delta_{i}\right)\left(1-\Delta_{m}\right) \sigma_{P}^{2}}{\Delta_{m}^{2} \sigma_{A}^{2}+\left(1-\Delta_{m}\right)^{2} \sigma_{P}^{2}}\left[\Delta_{m}\left(\sigma_{S A} \sigma_{A}+\sigma_{S P} \sigma_{P}\right)-\sigma_{S P} \sigma_{P}\right] d t \\
& \neq\left[\Delta_{i}\left(\sigma_{S A} \sigma_{A}+\sigma_{S P} \sigma_{P}\right)-\sigma_{S P} \sigma_{P}\right] d t=E\left[d R_{i}-r d t\right]
\end{aligned}
$$


which implies the failure of the conditional CAPM.

More interestingly, it is possible that a firm with higher returns has a lower beta. To see this, rewrite beta as

$$
\beta_{i}=\frac{\Delta_{i}\left[\Delta_{m}\left(\sigma_{A}^{2}+\sigma_{P}^{2}\right)-\sigma_{P}^{2}\right]+\left(1-\Delta_{m}\right) \sigma_{P}^{2}}{\Delta_{m}^{2} \sigma_{A}^{2}+\left(1-\Delta_{m}\right)^{2} \sigma_{P}^{2}} .
$$

While the expected return is increasing in $\Delta_{i}$ (which leads to a value premium) we have $\partial \beta_{i} / \partial \Delta_{i}<0$ if $\sigma_{A}^{2} / \sigma_{P}^{2}<\left(1-\Delta_{m}\right) / \Delta_{m}$, which holds when $\Delta_{m}$ is sufficiently small. Note that $\frac{\int_{i} X_{i} J_{i X}\left(K_{i}, X_{i}\right) d i}{\int_{i} J_{i}\left(K_{i}, X_{i}\right) d i}=1-\frac{\int_{i} K_{i} J_{i K}\left(K_{i}, X_{i}\right) d i}{\int_{i} J_{i}\left(K_{i}, X_{i}\right) d i}$, due to homogeneity, and hence $\Delta_{m}$ is small when $J_{K}$ is particularly high, that is, during good times. This implies that the excess market return and the conditional market betas are countercyclical.

In this model, the CAPM fails because there is a systematic factor that the CAPM does not price correctly; that is, the shocks to the price of capital goods. The bottom line is that we can generate the failure of the CAPM with relative ease compared with the effort involved in generating the correct cross-sectional distribution of stock returns and book-tomarket values simultaneously.

\section{Conclusion}

This paper presents a dynamic model of the firm with limited capital irreversibility and incomplete debt contracts in order to analyze the effects of financial leverage on investment and explain the cross-sectional differences in equity returns. This model can capture several regularities in the corporate finance and asset pricing literature in a parsimonious and tractable way.

Introducing debt into production-based asset pricing models opens several possibilities. For example, the model presented here could be extended with time-varying interest rates in a similar framework to Merton's (1973) intertemporal capital asset pricing model (ICAPM). This would serve two purposes. First, it would decrease the explanatory power of the conditional market beta for stock returns and get us one step closer to solving the value premium puzzle. Second, because firms with a high book-to-market ratio also have higher leverage, they will have greater exposure to interest rate shocks, further reinforcing the value premium. I hope that this paper will stimulate future research in this direction. 


\section{References}

Abel, Andrew B. and Janice C. Eberly. 1995. "Optimal Investment with Costly Reversibility.” Working Paper 5091. Cambridge, MA: National Bureau of Economic Research.

Abel, Andrew B. and Janice C. Eberly. 1996. "Optimal Investment with Costly Reversibility.” Review of Economic Studies 63(4): 581-593.

Berk, Jonathan B., Richard C. Green, and Vasant Naik. 1999. "Optimal investment, growth options and security returns.” Journal of Finance (54):1153-1607.

Bertola, Giuseppe and Ricardo J. Caballero. 1990. "Kinked Adjustment Costs and Aggregate Dynamics.” NBER Macroeconomics Annual 1990 5: 237-288.

Black, Fischer. 1972. "Capital Market Equilibrium with Restricted Borrowing." Journal of Business 45(3): 444-455.

Campbell, John Y. and Tuomo Vuolteenaho. 2004. "Bad Beta, Good Beta." American Economic Review 94(5): 1249-1275.

Carlson, Murray D., Adlai J. Fisher, and Ron Giammarino. 2004. "Corporate Investment and Asset Price Dynamics: Implications for the Cross Section of Returns." Journal of Finance 59(6): 2577-2603.

Cooper, Ilan. 2006. "Asset Pricing Implications of Nonconvex Adjustment Costs and Irreversibility of Investment." Journal of Finance 61(1): 139-170.

Dixit, Avinash K. 1993. The Art of Smooth Pasting. Chur, Switzerland: Harwood Academic Publishers.

Fischer, Edwin O., Robert Heinkel, and Josef Zechner. 1989. "Dynamic Capital Structure Choice: Theory and Tests." The Journal of Finance 44(1): 19-40.

Fama, Eugene F. and Kenneth R. French. 1992. "The Cross-Section of Expected Stock Returns." Journal of Finance 47: 427-465.

Fama, Eugene F. and Kenneth R. French. 1993. "Common Risk Factors in the Returns on Stocks and Bonds." Journal of Financial Economics 33: 3-56.

Gomes, Joao F. and Lukas Schmid. 2009. "Levered Returns.” Working Paper, University of Pennsylvania.

Grinblatt, Mark and Sheridan Titman. 2001. Financial Markets and Corporate Strategy, 2nd Edition. McGraw-Hill.

Hall, Robert E. 2004. "Measuring Factor Adjustment Costs." Quarterly Journal of Economics 119(3): 899-927.

Hayashi, Fumio. 2000. Econometrics. Princeton, NJ: Princeton University Press.

Lintner, John. 1965. "The Valuation of Risk Assets and the Selection of Risky Investments in Stock Portfolios and Capital Budgets." Review of Economics and Statistics 47(1): 221245. 
Livdan, Dmitry, Horacio Sapriza, and Lu Zhang. 2009. "Financially Constrained Stock Returns." Journal of Finance, forthcoming.

Lettau, Martin, and Jessica A. Wachter. 2007. "Why is Long-Horizon Equity Less Risky? A Duration-Based Explanation of the Value Premium." Journal of Finance 62: 55-92.

Merton, Robert C. 1973. “An Intertemporal Capital Asset Pricing Model." Econometrica 41(5): 867-887.

Modigliani, Franco and Merton H. Miller. 1958. "The Cost of Capital, Corporation Finance and the Theory of Investment." The American Economic Review 48(3): 261-297.

Sharpe, William F. 1964. "Capital Asset Prices: A Theory of Market Equilibrium under Conditions of Risk." Journal of Finance 19(3): 425-442.

Taylor, Jack. 2003. “Corporation Income Tax Brackets and Rates,1909-2002.” Statistics Income Bulletin, Fall.(http://www.irs.gov/pub/irs-soi//99corate.pdf).

Welch, Ivo. 2004. "Capital Structure and Stock Returns." Journal of Political Economy 112(1): 106-131.

Zhang, Lu. 2005. “The Value Premium.” Journal of Finance 60(1): 67-103.

\section{Appendix}

\subsection{Market Value and Stock Returns with Irreversibility and Finan- cial Leverage}

We can simplify our problem by defining $\tilde{q}(y, b) \equiv q(y, b)+\bar{m} / r$. Therefore, equations (2), (3), and (4) can be rewritten as

$$
\begin{aligned}
r \tilde{q}(y, b) & =\bar{h} y^{\gamma}+\mu y \tilde{q}_{y}(y, b)+\frac{1}{2} \sigma^{2} y^{2} \tilde{q}_{y y}(y, b) \\
\tilde{q}\left(y_{L}(b), b\right) & =\eta-b+\bar{m}(b) / r \equiv l(b) \text { and } \tilde{q}_{y}\left(y_{L}(b), b\right)=0 \\
\tilde{q}\left(y_{U}(b), b\right) & =1-b+\bar{m}(b) / r \equiv u(b) \text { and } \tilde{q}_{y}\left(y_{U}(b), b\right)=0 .
\end{aligned}
$$

This makes the solution of the differential equation similar to the one in Abel and Eberly (1996), which is a special case of my model that excludes leverage and the risk preferences of investors. Following their analysis, I define the following functions

$$
\begin{aligned}
\rho(x) & =-\frac{1}{2} \sigma^{2} x^{2}-\left(\mu-\frac{1}{2} \sigma^{2}\right) x+r \\
\theta(x) & =\frac{x^{\alpha_{P}}-x^{\gamma}}{x^{\alpha_{P}}-x^{\alpha_{N}}} \\
\phi(x) & =\frac{1}{\rho(\gamma)}\left\{1-\frac{\gamma}{\alpha_{N}} \theta(x)-\frac{\gamma}{\alpha_{P}}[1-\theta(x)]\right\},
\end{aligned}
$$


where $\alpha_{P}$ and $\alpha_{N}$ are the roots of the quadratic equation $\rho(x)=0$ and satisfy $\alpha_{P}>1>$ $\gamma>0>\alpha_{N}$. Then, the solution of this differential equation should be of the form

$$
\tilde{q}(y, b)=H y^{\gamma}+C_{P}(b) y^{\alpha_{P}}+C_{N}(b) y^{\alpha_{N}}
$$

The reason is that $b$ appears only in the boundary conditions for $\tilde{q}$ but not in the differential equation.

Define $H(\gamma) \equiv \bar{h} / \rho(\gamma)$ and $G(b) \equiv y_{U}(b) / y_{L}(b)$. Then, the solution of the differential equation for $\tilde{q}(y, b)$ is given by

$$
\begin{aligned}
\tilde{q}(y, b)= & H(\gamma) y_{L}(b)^{\gamma} \\
& *\left[\left(\frac{y}{y_{L}(b)}\right)^{\gamma}-\frac{\gamma}{\alpha_{P}}[1-\theta(G(b))]\left(\frac{y}{y_{L}(b)}\right)^{\alpha_{P}}-\frac{\gamma}{\alpha_{N}} \theta(G(b))\left(\frac{y}{y_{L}(b)}\right)^{\alpha_{N}}\right],
\end{aligned}
$$

where $G(b)$ is implicitly defined by

$$
\frac{u(b)}{l(b)} \phi(G(b))-G(b)^{\gamma} \phi(1 / G(b))=0
$$

and the values of boundaries are given by

$$
\bar{h} y_{U}(b)^{\gamma}=\frac{u(b)}{\phi(1 / G(b))} \text { and } \bar{h} y_{L}(b)^{\gamma}=\frac{l(b)}{\phi(1 / G(b))} \text {. }
$$

Using this solution, the value function can be found by simply integrating $q(X / K)$ over $K$ to ger

$$
\begin{aligned}
& J(K, X, b) \\
= & H(\gamma) y_{L}^{\gamma}\left[\frac{1}{1-\gamma} \frac{X^{\gamma} K^{1-\gamma}}{y_{L}(b)^{\gamma}}-\frac{\gamma}{\alpha_{P}} \frac{1-\theta(G)}{1-\alpha_{P}} \frac{X^{\alpha_{P}} K^{1-\alpha_{P}}}{y_{L}(b)^{\alpha_{P}}}-\frac{\gamma}{\alpha_{N}} \frac{\theta(G)}{1-\alpha_{N}} \frac{X^{\alpha_{N}} K^{1-\alpha_{N}}}{y_{L}(b)^{\alpha_{N}}}\right] \\
& -\frac{\bar{m}(b)}{r} K \\
= & J^{A P}+J^{G}+J^{D}-\frac{\bar{m}(b)}{r} K .
\end{aligned}
$$

Now we focus on stock returns. Apply Ito's Lemma to equity value in the inaction

\footnotetext{
${ }^{21}$ The solution is identical to that of Abel and Eberly (1996) once the purchase and resale prices of capital in their model are substituted with $u(b)$ and $l(b)$, respectively. Therefore, I omit the lengthy details of the calculus that leads to the solution, but they are available upon request.

${ }^{22}$ Direct integration of $q(y)$ would yield a constant of integration that should have the form $D_{X}(b) X$, due to the homogeneity property of the value function. However, direct substitution of $J(X, K)$ into the HJB equation shows immediately that $D_{X}(b)$ should be zero.
} 
region, $J(K, X)$

$$
d J=\left(\mu_{X} X J_{X}+\frac{1}{2} \sigma^{2} X^{2} J_{X X}\right) d t+\sigma X J_{X} d w .
$$

Use the relationship $\mu=\mu_{X}-\sigma_{S} \sigma_{A}$ and the HJB equation $r J=\pi+\mu X J_{X}+\frac{1}{2} \sigma^{2} X^{2} J_{X X}$ to get

$$
\frac{1}{d t} E\left(\frac{d J}{J}\right)=-\frac{\pi}{J}+r+\sigma_{S} \frac{J_{X} X}{J} .
$$

Plugging this expression into the return formula gives the excess returns

$$
\frac{1}{d t} E(d R)-r=\frac{1}{d t} E\left(\frac{\pi d t+d J}{J}\right)-r=\sigma_{S} \sigma_{A} \frac{J_{X} X}{J} .
$$

To show that the returns are increasing in $y$, first note that we can write the excess returns as

$$
\begin{aligned}
\frac{1}{d t} E(d R)-r & =\left(\gamma \frac{J^{A P}}{J+\bar{m} / r K}+\alpha_{P} \frac{J^{G}(K, X)}{J+\bar{m} / r K}+\alpha_{N} \frac{J^{D}(K, X)}{J+\bar{m} / r K}\right)\left(1+\frac{\bar{m} / r K}{J}\right) \sigma_{S} \sigma_{A} \\
& =\left(\gamma s_{A P}+\alpha_{P} s_{G}+\alpha_{N} s_{D}\right)\left(1+\frac{\bar{m} / r K}{J}\right) \sigma_{S} \sigma_{A},
\end{aligned}
$$

where the first term decomposes the total business risk into assets-in-place, the growth option and the disinvestment option, while the second term captures the Modigliani-Miller effect.

\subsection{Proof of Proposition 2}

From the previous section, we know that the following equation builds the connection between the investment and disinvestment boundary and financial leverage

$$
\frac{u(b)}{l(b)} \phi(G(b))-G(b)^{\gamma} \phi(1 / G(b))=0
$$

which we can rewrite as

$$
\frac{u(b)}{l(b)}=\frac{G(b)^{\gamma} \phi(1 / G(b))}{\phi(G(b))} .
$$

It is easy to show that the left side of this equation is increasing in $b$, and hence the right side of the equation should be increasing in $b$. Abel and Eberly (1995) show in a lengthy and tedious proof that $\frac{G^{\gamma} \phi(1 / G)}{\phi(G)}$ is increasing in $G$. Suppose $G^{\prime}(b) \leq 0$. Then, the left side would be weakly decreasing in $b$, causing a contradiction. 


\subsection{Proof of Proposition 3}

Debt is strictly preferable to equity financing if the marginal value of debt net of the cost of financing is positive, that is if $J(K, X, b)+b K-c b K$ is increasing in $b$ or $J_{b}(K, X, b)+$ $(1-c) K \geq 0$. We should first find $J_{b}(K, X, b)$. Remember that the market value of equity has the form

$$
J(K, X, b)=\bar{H} X^{\gamma} K^{1-\gamma}+\bar{D}_{P}(b) X^{\alpha_{P}} K^{1-\alpha_{P}}+\bar{D}_{N}(b) X^{\alpha_{N}} K^{1-\alpha_{N}}-\frac{\bar{m}(b)}{r} K .
$$

Because $\bar{D}_{P}(b)$ and $\bar{D}_{N}(b)$ are highly non-linear functions of $b$ and because $G(b)$ is an implicitly defined function, a brute force approach would be too tedious. Instead, we will focus on the value-matching and smooth pasting conditions. Using the functional form and homogeneity of the market value of equity in $X$ and $K$, the value-matching and smooth pasting conditions for the marginal value of capital can be expressed as

$$
\begin{aligned}
\bar{H} y_{U}(b)^{\gamma}+\left(1-\alpha_{P}\right) \bar{D}_{P}(b) y_{U}(b)^{\alpha_{P}}+\left(1-\alpha_{N}\right) \bar{D}_{N}(b) y_{U}(b)^{\alpha_{N}} & =1-\tau b+(1-\tau) \frac{\delta}{r} \\
\bar{H} y_{L}(b)^{\gamma}+\left(1-\alpha_{P}\right) \bar{D}_{P}(b) y_{L}(b)^{\alpha_{P}}+\left(1-\alpha_{N}\right) \bar{D}_{N}(b) y_{L}(b)^{\alpha_{N}} & =1-\tau b+(1-\tau) \frac{\delta}{r} \\
\bar{H} \gamma y_{U}(b)^{\gamma}+\left(1-\alpha_{P}\right) \alpha_{P} \bar{D}_{P}(b) y_{U}(b)^{\alpha_{P}}+\left(1-\alpha_{N}\right) \alpha_{N} \bar{D}_{N}(b) y_{U}(b)^{\alpha_{N}} & =-\tau \\
\bar{H} \gamma y_{L}(b)^{\gamma}+\left(1-\alpha_{P}\right) \alpha_{P} \bar{D}_{P}(b) y_{L}(b)^{\alpha_{P}}+\left(1-\alpha_{P}\right) \alpha_{N} \bar{D}_{N}(b) y_{L}(b)^{\alpha_{N}} & =-\tau .
\end{aligned}
$$

If we take the derivatives of the first two equations with respect to $b$ and plug the last two equations in the resulting expressions we get

$$
\begin{aligned}
& D_{P}^{\prime}(b) y_{U}^{\alpha_{P}}+D_{N}^{\prime}(b) y_{U}^{\alpha_{N}}=-\tau \\
& D_{N}^{\prime}(b) y_{U}^{\alpha_{P}}+D_{P}^{\prime}(b) y_{U}^{\alpha_{N}}=-\tau,
\end{aligned}
$$

which gives

$$
\begin{aligned}
D_{P}^{\prime}(b) & =-\frac{\tau}{1-\alpha_{P}} \frac{1-G(b)^{\alpha_{N}}}{G(b)^{\alpha_{P}}-G(b)^{\alpha_{N}}} \frac{1}{y_{L}(b)^{\alpha_{P}}} \\
D_{N}^{\prime}(b) & =-\frac{\tau}{1-\alpha N} \frac{G(b)^{\alpha_{P}}-1}{G(b)^{\alpha_{P}}-G(b)^{\alpha_{N}}} \frac{1}{y_{L}(b)^{\alpha_{N}}}
\end{aligned}
$$

As a result, the derivative of total firm value as a function with respect to leverage is given by

$J_{b}(K, X, b)=-\tau\left[\frac{1-G^{\alpha_{N}}}{G^{\alpha_{P}}-G^{\alpha_{N}}} \frac{1}{1-\alpha_{P}}\left(\frac{y}{y_{L}}\right)^{\alpha_{P}}+\frac{G^{\alpha_{P}}-1}{G^{\alpha_{P}}-G^{\alpha_{N}}} \frac{1}{1-\alpha_{N}}\left(\frac{y}{y_{L}}\right)^{\alpha_{N}}+\frac{1-\tau}{\tau}\right] K$, 
where $b$ has been dropped in $G(b)$ for the sake of brevity. Therefore the marginal value of debt is given by

$$
\begin{aligned}
J_{b}+(1-c) K= & \tau\left[1-\frac{1-G^{\alpha_{N}}}{G^{\alpha_{P}}-G^{\alpha_{N}}} \frac{1}{1-\alpha_{P}}\left(\frac{y}{y_{L}}\right)^{\alpha_{P}}-\frac{G^{\alpha_{P}}-1}{G^{\alpha_{P}}-G^{\alpha_{N}}} \frac{1}{1-\alpha_{N}}\left(\frac{y}{y_{L}}\right)^{\alpha_{N}}\right] K \\
& -c K .
\end{aligned}
$$

Since $G>1$ and $\alpha_{P}>1>0>\alpha_{N}$, the term in square brackets is decreasing in $y$. Therefore, debt is the preferred for of financing at every state if $J_{b}+(1-c) K>0$ at $y=y_{L}$. Substituting $y=y_{L}$ above reduces our condition to

$$
c<c^{*}(b)=\tau\left[1-\frac{1-G^{\alpha_{N}}}{G^{\alpha_{P}}-G^{\alpha_{N}}} \frac{1}{1-\alpha_{P}}-\frac{G^{\alpha_{P}}-1}{G^{\alpha_{P}}-G^{\alpha_{N}}} \frac{1}{1-\alpha_{N}}\right] .
$$

Since $G>1$ and $\alpha_{P}>1>0>\alpha_{N}$, the second term is on the right side is negative and the third term is less than 1 . Moreover, the right side of this equation is decreasing in $G$, and we already know from the proof of the previous proposition that $G^{\prime}(b)>0$. Therefore, $c^{*}(b)>0$ and $c^{* \prime}(b)<0$. The minimum for $c^{*}(b)$ is then attained when $G \rightarrow \infty$, that is, $c^{*}=1-1 /\left(1-\alpha_{N}\right)$. So, if $c<1-1 /\left(1-\alpha_{N}\right)$, then debt is always preferable regardless of state and degree of irreversibility.

\subsection{Proof of Proposition 4}

Using the results from the last section we have

$$
J_{b}+K=\tau\left[1-\frac{1-G^{\alpha_{N}}}{G^{\alpha_{P}}-G^{\alpha_{N}}} \frac{1}{1-\alpha_{P}}\left(\frac{y}{y_{L}}\right)^{\alpha_{P}}-\frac{G^{\alpha_{P}}-1}{G^{\alpha_{P}}-G^{\alpha_{N}}} \frac{1}{1-\alpha_{N}}\left(\frac{y}{y_{L}}\right)^{\alpha_{N}}\right] K
$$

which attains its minimum value for $y=y_{L}$. So, it is enough to show that this value is positive once we substitute $y=y_{L}$, i.e. that

$$
\tau\left[1-\frac{1-G^{\alpha_{N}}}{G^{\alpha_{P}}-G^{\alpha_{N}}} \frac{1}{1-\alpha_{P}}-\frac{G^{\alpha_{P}}-1}{G^{\alpha_{P}}-G^{\alpha_{N}}} \frac{1}{1-\alpha_{N}}\right]>0 .
$$

Again, since $G>1$ and $\alpha_{P}>1>0>\alpha_{N}$, the second term is on the right side is negative and the third term is less than 1 . Therefore, the term in square brackets should be positive. Since $J_{b}+K>0$, one of the smooth pasting conditions at debt adjustment is not satisfied, and hence it is not optimal to readjust debt. 


\subsection{Market Value and Stock Returns with Investment Irreversibility Only}

The market value of equity under this setting is the same, except that we should set $b=\delta=$ 0 . Let $H(\gamma) \equiv h / \rho(\gamma)$ and $G \equiv y_{U} / y_{L}$. Then, the solution of the differential equation for $q(y)$ where $y \equiv X / K$ is given by

$$
q(y)=H(\gamma) y_{L}^{\gamma}\left[\left(\frac{y}{y_{L}}\right)^{\gamma}-\frac{\gamma}{\alpha_{P}}[1-\theta(G)]\left(\frac{y}{y_{L}}\right)^{\alpha_{P}}-\frac{\gamma}{\alpha_{N}} \theta(G)\left(\frac{y}{y_{L}}\right)^{\alpha_{N}}\right]
$$

where $G$ is the solution of

$$
\frac{1}{\eta} \phi(G)-G^{\gamma} \phi\left(G^{-1}\right)=0
$$

Using this solution, the value function can be found by simply integrating $q(X / K)$ over $K$ to get $^{23}$

$$
\begin{aligned}
& J(K, X) \\
= & H(\gamma) y_{L}^{\gamma}\left[\frac{1}{1-\gamma} \frac{X^{\gamma} K^{1-\gamma}}{y_{L}^{\gamma}}-\frac{\gamma}{\alpha_{P}} \frac{1-\theta(G)}{1-\alpha_{P}} \frac{X^{\alpha_{P}} K^{1-\alpha_{P}}}{y_{L}^{\alpha_{P}}}-\frac{\gamma}{\alpha_{N}} \frac{\theta(G)}{1-\alpha_{N}} \frac{X^{\alpha_{N}} K^{1-\alpha_{N}}}{y_{L}^{\alpha_{N}}}\right] \\
= & J^{A P}+J^{G}+J^{D} .
\end{aligned}
$$

To show that the returns are increasing in $y$, first note that we can write the excess returns as

$$
\begin{aligned}
\frac{1}{d t} E(d R)-r & =\left(\gamma \frac{J^{A P}(K, X)}{J(K, X)}+\alpha_{P} \frac{J^{G}(K, X)}{J(K, X)}+\alpha_{N} \frac{J^{D}(K, X)}{J(K, X)}\right) \sigma_{S} \sigma_{A} \\
& =\left(\gamma \frac{J^{A P}(1, y)}{J(1, y)}+\alpha_{P} \frac{J^{G}(1, y)}{J(1, y)}+\alpha_{N} \frac{J^{D}(1, y)}{J(1, y)}\right) \sigma_{S} \sigma_{A} \\
& =\left(\gamma+\left(\alpha_{P}-\gamma\right) \frac{J^{G}(1, y)}{J(1, y)}+\left(\alpha_{N}-\gamma\right) \frac{J^{D}(1, y)}{J(1, y)}\right) \sigma_{S} \sigma_{A} .
\end{aligned}
$$

Now, it is easy to show that $J^{G}(1, y) / J(1, y)$ is increasing in $y$ and $J^{D}(1, y) / J(1, y)$ is decreasing in $y$ by taking the derivatives. Since $\alpha_{P}-\gamma>0$ and $\alpha_{N}-\gamma<0$, this last expression should be increasing in $y$.

\footnotetext{
${ }^{23}$ Direct integration of $q(y)$ would yield a constant of integration that should depend linearly on $X$ due to the homogeneity property of the value function. However, direct substitution of $J(X, K)$ in to the HJB equation shows immediately that this term should be zero.
} 


\subsection{The Long-Run Distribution of Book-to-Market Values}

In this section we will calculate the stationary long-run distribution of book-to-market values. In line with Security Exchange Commission rules, we assume that firms should exit the stock exchange market if their value falls below a particular threshold. In order to have a stationary distribution, we also assume that each firm that leaves the stock market is replaced by another firm that enters the market after paying a fixed cost linearly proportional to its capital. This later assumption guarantees that the entry point for all firms is the same and is characterized by $y=\bar{y}$, as a result of the homogeneity of the maximization problem in $X$ and $K 24$

Using the model parameters, we can calculate the cross-section of returns in the long run by looking at the stationary distribution of $y$ between two barriers, $y_{L}$ and $y_{U}$. The exitentry mechanism discussed above implies that the long-run cross-sectional distribution of $y$ will be the same as the long-run distribution of a process with a resetting barrier at $y_{L}$ where the target after resetting is $\bar{y}$. Note that the case without exit is a special case of this mechanism, where $\bar{y}=y_{U}$ and no entry cost is a special case with $\bar{y}=y_{L}$.

Finally, we assume that a firm leaves the sample if $y=y^{*}>y_{L}$. This assumption serves two purposes: First, firms with very low market values will leave the sample, in accordance with the Security Exchange Commission rule that requires delisting of companies whose share price falls below a certain value. This property is also evident in the data, because the highest cross-sectional book-to-market value in different years is capped at around 30, whereas we should observe much higher book-to-market values if firms with very low market values were not delisted. Second, because this assumption caps book-to-market values, it will improve the fit of the average book-to-market values and stock returns at the highest decile.

The law of motion for $y$ is given by $d y / y=\mu_{X} d t+\sigma d w$. Define $z \equiv \log y, z_{L} \equiv \log y_{L}$, and $z_{U} \equiv \log y_{U}$, and let $g(z)$ be the long-run distribution of $z$. Bertola and Cabellero (1990) show that $g(z)$ is given by the solution of the Kolmogorov forward equation

$$
g^{\prime \prime}(z)=2 \frac{\left(\mu_{X}-\frac{1}{2} \sigma^{2}\right)}{\sigma^{2}} g^{\prime}(z)
$$

\footnotetext{
${ }^{24}$ The same entry point is a simplifying assumption. Different entry points would not affect the functional form for the market value of equity, since debt capacity is independent of the state variables.
} 
separately for the regions $\left[z_{L}, \bar{z}\right)$ and $\left(\bar{z}, z_{U}\right]$ with the following boundary conditions

$$
\begin{aligned}
g^{\prime}\left(\bar{z}^{-}\right) & =g\left(\bar{z}^{+}\right)+g^{\prime}\left(z_{L}^{+}\right) \\
g^{\prime}\left(z_{U}\right) & =2 \frac{\left(\mu_{X}-\frac{1}{2} \sigma^{2}\right)}{\sigma^{2}} g\left(z_{U}\right) \\
g\left(z^{*}\right) & =0
\end{aligned}
$$

where $g\left(z^{+}\right)$is the right limit and $g\left(z^{-}\right)$is the left limit of the distribution function. We also have the integral condition

$$
\int_{z_{L}}^{z_{U}} g(z) d z=1
$$

Once we find $g(z)$, we can find the distribution of $y$ using the transformation $\varphi(y)=$ $g(\ln y)$. A little algebra shows that the long-run distribution of $y$ is given by

$$
\varphi(y)=\left\{\begin{array}{ccc}
\left(A_{1} y^{\left(2 \mu_{X}-\sigma^{2}\right) / \sigma^{2}}+B_{1}\right) / y & \text { if } y^{*}<y<\bar{y} \\
A_{2} y\left(2 \mu_{X}-\sigma^{2}\right) / \sigma^{2}-1 & \text { if } \quad \bar{y} \leq y<y_{U} \\
0 & \text { otherwise }
\end{array}\right.
$$

where $A_{1}, A_{2}$ and $B_{1}$ satisfy

$$
\begin{aligned}
& \left(y^{*}\right)^{\left(2 \mu_{X}-\sigma^{2}\right) / \sigma^{2}} A_{1}+B_{1}=0 \\
& \left(\bar{y}^{\left(2 \mu_{X}-\sigma^{2}\right) / \sigma^{2}}-\left(y^{*}\right)^{\left(2 \mu_{X}-\sigma^{2}\right) / \sigma^{2}}\right) A_{1}-\bar{y}^{\left(2 \mu_{X}-\sigma^{2}\right) / \sigma^{2}} A_{2}=0 \\
& \frac{\bar{y}^{\left(2 \mu_{X}-\sigma^{2}\right) / \sigma^{2}}-\left(y^{*}\right)^{\left(2 \mu_{X}-\sigma^{2}\right) / \sigma^{2}}}{\left(2 \mu_{X}-\sigma^{2}\right) / \sigma^{2}} A_{1}+\frac{y_{U}^{\left(2 \mu_{X}-\sigma^{2}\right) / \sigma^{2}}-\bar{y}^{\left(2 \mu_{X}-\sigma^{2}\right) / \sigma^{2}}}{\left(2 \mu_{X}-\sigma^{2}\right) / \sigma^{2}} A_{2}+\ln \left(\frac{\bar{y}}{y^{*}}\right) B_{1}=1 .
\end{aligned}
$$

Then, we can write market-to-book values as $J /(1-b) K=V(y) /(1-b)$. Once we define the function $\omega(y)=V(y) /(1-b)$, the long-run distribution of market-to-book values, $m b$, is given by

$$
f(m b)=\varphi\left(\omega^{-1}(m b)\right)\left|\frac{d \omega^{-1}(m b)}{d(m b)}\right|
$$

for $V\left(y_{U}\right) /(1-b) \geq m b \geq V\left(y_{L}\right) /(1-b)$, and zero otherwise.

Once we have the long-run distribution of book-to-market values, I use the long-run distribution derived from the data in order to estimate the model parameters using maximum likelihood. 